\title{
Analysis on Present Situation and Countermeasures of Pension Service industry in Beijing-Tianjin-Hebei
}

\author{
Mei-Qi FENG ${ }^{1, a}$,Yong-Gang ZHANG ${ }^{2, b}$,Yan-Hong YANG ${ }^{1, c}$, Cui-You YAO ${ }^{1, d, *}$ \\ ${ }^{1}$ Information School, Capital University of Economics and Business, Beijing, China \\ ${ }^{2}$ City Union SAC/TC 426, Beijing, China \\ a852828641@qq.com, bZyg0521@126.com, cyyh@cueb.edu.cn, dycy@cueb.edu.cn \\ ${ }^{*}$ Corresponding author
}

Keywords: Beijing-Tianjin-Hebei; Pension Service Industry; Collaborative Development.

\begin{abstract}
The aging population in the Beijing-Tianjin-Hebei region is currently accelerating sharply and in the stage of rapid development, then the development of pension services industry problem comes out. Although the Beijing-Tianjin-Hebei integration process continues to promote, there are still many problems in the process of the development of pension services industry. In this article, we will analyze the current situation of pension service industry in Beijing-Tianjin-Hebei. Based on the problems, in order to promote the coordinated development of the three region's pension service industry, some corresponding countermeasures will be put forwarded.
\end{abstract}

\section{Introduction}

In recent years, the problem of aging population is becoming more and more serious, with the policy of Beijing-Tianjin-Hebei coordinated development putting forwarded, the coordinated development of pension services industry is becoming very important. In order to promote the formation of Beijing-Tianjin-Hebei metropolitan area, the government has adopted a series of measures, but with little success, the phenomenon of "getting old before getting rich" (Wen Kui, 2013) appears in Beijing-Tianjin-Hebei. Even though the opening of the two child policy, we can't control the speed of population aging within a short period of time, then the development of service industry is particularly important.

First, we need make clear the content of the pension service industry before developing it, not all of the pension services are available for industrial development. In the narrow sense, the "service" refers to of the pension services, mainly focused on providing housekeeping services for the elderly, care, spiritual comfort and other life care services (Chen Yi, 2010). This kind of pension service is the new service industry which needs to develop in China. It is also the focus of the development of pension services in Beijing-Tianjin-Hebei.

On April 30, 2015, the Political Bureau of the CPC Central Committee examined and adopted the "Beijing-Tianjin-Hebei collaborative development plan", the coordinated development of Beijing-Tianjin-Hebei is officially as a major national strategy. To support the Beijing-Tianjin-Hebei integration strategy, promoting the coordinated development of pension services is conducive to the realization of three complementary advantages of pension resources and common progress and to provide support for solving the Beijing-Tianjin-Hebei pension problem. In this article, the Beijing-Tianjin-Hebei pension service industry status will be analyzed, the existing problems will be founded out, and the countermeasures and suggestions will be put forwarded.

\section{Journals Reviewed}

In view of the coordinated development of pension service industry in Beijing-Tianjin-Hebei, domestic scholars have done a lot of research. Sun Jianfu and Dai Luwei (2015) thought that the main goal of the coordinated development of pension service industry in Beijing-Tianjin-Hebei is to realize 
the three complementary advantages of pension resources, to meet their needs to provide pension services for three region elderly people, and to improve medical service quality and ability. In order to achieve the target, we need adhere to the dual regulation of the market and the government, share pension resources and the principle of the supremacy of the interests of the elderly (Sun Jianfu and Dai Luwei, 2015). However, the wish for provide for the aged in different places is also an essential factor in the development of pension services industry in Beijing-Tianjin-Hebei. Now the elderly in Beijing-Tianjin-Hebei region is concentrated mostly in Beijing, Tianjin and other big city. But the land of Beijing is limited and expensive, which hinders the development of pension service industry. Besides metropolitan environment is not suitable for the elderly to live, then Hebei has the advantage of developing the pension service industry ( $\mathrm{Liu} \mathrm{Li}, 2016$ ). And due to the accelerated integration of Beijing-Tianjin-Hebei, for the children who may move to work in Hebei, the elderly are more willing to follow their children to Hebei for pension. This makes the development of pension services industry in Beijing-Tianjin-Hebei have broad prospects, but there are still many problems in its development. The experts and scholars gave some suggestions, mainly on accelerating the construction of appropriate social pension service system (Luo Haiping and Ling Dan, 2013), becoming specialization and professionalism, building a high quality service team for aged (Wang Jia, 2011), changing the previous development model of collective oriented but single investment, developing more financing channels, establishing a long-term effective integration mechanism (Liu Yue, 2015), increasing policy support, improving relevant laws and regulations system (Xiang Tian, 2012), learning from the successful experience of foreign pension and establishing a sound legal system (Zhang Panpan, 2016).

\section{The Present Status of Population Aging In Beijing-Hebei-Tianjin}

The aging population of Beijing-Tianjin-Hebei region is an important factor that should not be ignored in the process of the coordinated development of pension services industry in Beijing-Tianjin-Hebei. According to the international definition of the aging society, if the population of the people over 65 years old occupies more than $7 \%$ of the whole population in the region, this area can be considered as having entered into the aging society. According to this definition, what is the situation of Beijing-Tianjin-Hebei region? In this paper, the relevant data of the Chinese Statistical Yearbook in $2006 \sim 2014$ years were collected, as shown in Figure. 1.

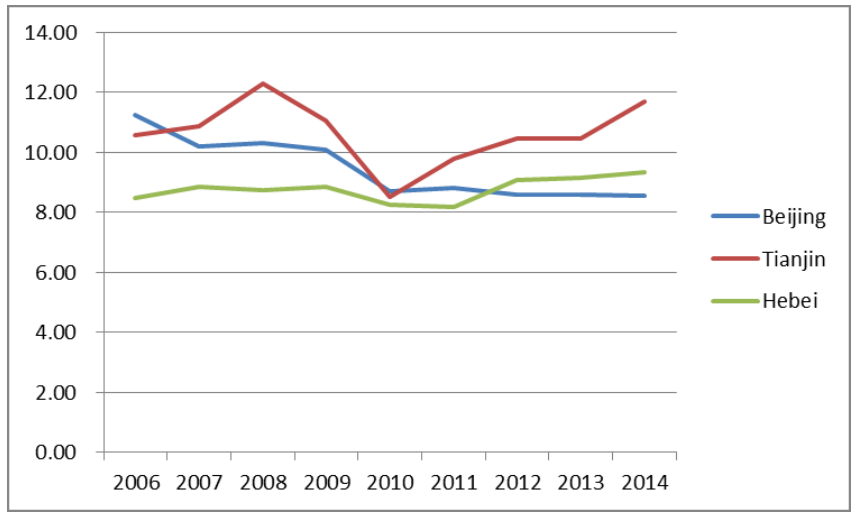

Figure. 1 the percentage of over 65 years old in Beijing, Tianjin and Hebei (\%)

From Figure.1, we can see that the percentage of the population over 65 years old in three regions has outnumbered 7\% in the statistical year. Among them, the population over the age of 65 in Beijing decreased year by year, and the graph showed a slight downward trend. The percentage of over 65 years old in Tianjin showed a wave state, but from the data between 2010 and 2014, we can see that the aging trend is rising year by year. Although the population over 65 years old in Hebei declined in 2008 2011, the overall trend of aging is still in a small increase. According to the above, we can see that the aging situation is slightly different in Beijing, Tianjin and Hebei. 


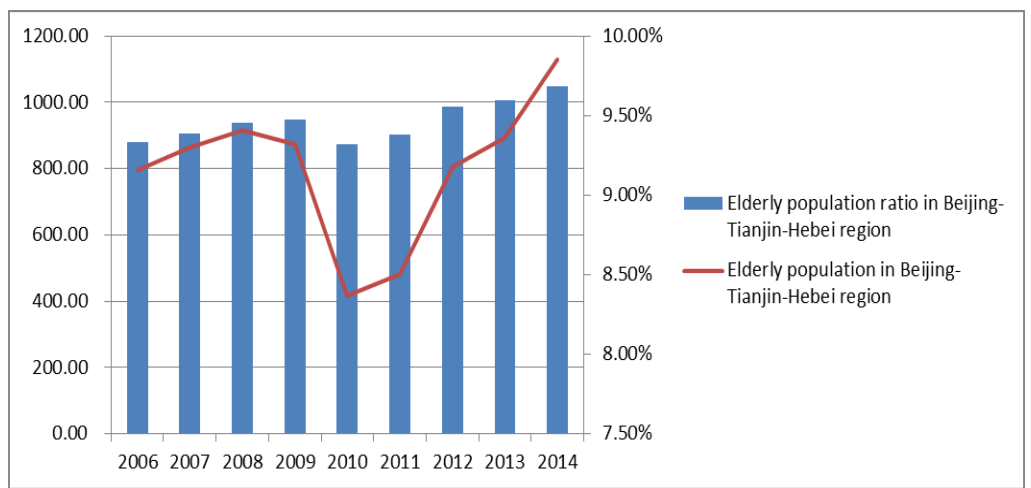

Figure.2 The elderly population (ten thousand) and ratio (\%) in Beijing-Tianjin-Hebei region

Figure. 2 shows the population and the proportion of the population over 65 years old in Beijing-Tianjin-Hebei region. As can be seen from Fig.2, the percentage of 65years old and above population presents fluctuation trend in Beijing-Tianjin-Hebei region. It increases from 2006 to 2008 year by year, in the year of 2009 and 2010 it's in the inflection point, followed by an increase year by year.

For the population development in Beijing-Tianjin-Hebei region, which is affected by the reduction of birth rate and the increase in the average life expectancy, the elderly population in Beijing-Tianjin-Hebei region presents a growth trend. According to the above analysis, at the beginning of the 2006, Beijing-Tianjin-Hebei region has entered the aging society, making the "getting old before getting rich" problem become serious.

"Development reports in Beijing-Tianjin-Hebei region" pointed out that solving the "getting old before getting rich" problem becomes urgent. The natural population growth of Beijing-Tianjin-Hebei region is slow. The natural population growth rate of Beijing and Tianjin is less than 4\%o, and that is less than $7 \%$ in Hebei. The main reason for the increase of population in Beijing, Tianjin and Hebei is the increase of migrant population size in Beijing and Tianjin (about 500 thousand people a year). In addition, according to the analysis and forecast on the regional structure of population from "Development reports in Beijing-Tianjin-Hebei region", the proportion of the labor force in the area of Beijing-Tianjin-Hebei region will continue to decline, down from $77 \%$ in 2010 to about $73 \%$ or $72 \%$ in 2020 . While the number of children (0-14years old) and the elderly (aged 65 and above) will show growth trend, as the pace of growth of the elderly population is significantly faster than that of the children, aging has become more serious.

The report notes that although the proportion of working age population in Beijing-Tianjin-Hebei region is low, due to the population of moving to Beijing and Tianjin is mostly the working age of young people, the absolute number of labor is sufficient. It is expected that in 2020, the Beijing-Tianjin-Hebei region labor supply is between 8473 and 8794 million, which reflects that Beijing-Tianjin-Hebei region can still enjoy a period of labor dividends in the background of accelerated urbanization and a large number of farmers moving out of the countryside. For the analysis of the next ten years, on one hand, the Beijing-Tianjin-Hebei region labor supply is still adequate, the employment situation is still grim; on the other hand, the degree of aging is increasing, public services and social security pressures increase. Therefore, solving a large number of labor employment and "getting old before getting rich" problem become the key to the future development of Beijing-Tianjin-Hebei region.

\section{The Present Status of Pension Service Industry in Beijing-Tianjin-Hebei}

\section{General Situation}

June 16, 2016, the civil administration department of Beijing, Tianjin and Hebei signed the "Beijing, Tianjin and Hebei pension work collaborative development cooperation agreement (2016-2020)". 
Three places strive to work together in the next five years to solve the Identity barriers and household registration barriers on the welfare of the elderly and pension services, to support the aged in different areas freely.

According to the agreement, three places are overall planning for construction of pension service area. Among them, relying on the rich traditional Chinese medicine resources in Hebei, Shijiazhuang City, we can create a medical service for the characteristics of the pension service gathering area. Relying on the rich ecological resources on Zhangjiakou City and Chengde City, we can build the Beijing-Tianjin-Hebei migratory pension service area. Relying on the ocean, summer resources and geographical advantages in Tangshan City and Qinhuangdao City, we can build a Beijing-Tianjin-Hebei leisure, health, entertainment, tourism as one of the pension service area. At the same time, Beijing, Tianjin and Hebei open up the policy of convergence channels and formulate relevant development support and supporting policies in accordance with the principle of old-age support policies of following the elderly. To promote the policy implementing, as experimental unit, Tianjin Wuqing, Hebei Gaobeidian and other regions can enjoy the Beijing pension beds operating subsidies, agencies comprehensive liability insurance, health insurance policy interoperability, etc.

Hebei, and Tianjin around the Beijing, has begun to implement the policy, or started construction, or put into operation all kinds of pension projects. However, the current policy can play an effective role in the trial, which will appear in the process of implementing. Whether it can really fit the needs of the elderly pension, it takes time to prove.

\section{The Pension Industry Status}

In the short period of two years, the pension industry is constantly creating a new pattern. Perhaps in the huge pension growing demand, the linkage of Beijing-Tianjin-Hebei pension industry is still somewhat immature, a number of explorations have just started, but from the perspective of acceleration this year, the regional pension industrial development has taken shape.

According to the statistics, by the end of 2016, the Beijing municipality has 600 pension institutions, 131 thousand and 518 beds. Tianjin city has 428 pension institutions, 69 thousand and 456 beds. Hebei province has 1283 pension institutions, the total number of beds is 197 thousand and 200. Affected by the capital, land, profit and lost and other factors, the average area of social pension institutions is less than national pension institutions, but the average bed number of social pension institutions is more than that of national. The fees scale of pension institutions are generally related to the standard of care for the elderly and living conditions. Beijing-Tianjin-Hebei region pension charges are illustrated in Table 1. According to the health of the elderly, most of the pension agency charge is divided into self-cared, semi-self-cared, the basically cannot self-cared and completely cannot self-cared, as well as combined with the number of living standards. The charges standard of public pension institutions is lower than private pension institutions. Meanwhile, it is also associated with the region. The charges in Beijing and Tianjin are higher than in that in Hebei, and the charge in city is higher than that in country.

Table 1 Pension institutions charge in Beijing-Tianjin-Hebei (yuan/year/person)

\begin{tabular}{|lcccc|}
\hline City & self-cared & $\begin{array}{l}\text { semi-self-c } \\
\text { ared }\end{array}$ & $\begin{array}{l}\text { basically can't } \\
\text { self-cared }\end{array}$ & completely can't self-cared \\
\hline $\begin{array}{l}\text { Beijing } \\
\text { Municipality }\end{array}$ & $2700-3000$ & $3300-3600$ & $3900-4200$ & $4500-5000$ and above \\
\hline $\begin{array}{l}\text { Tianjin } \\
\text { Municipality }\end{array}$ & $1900-2400$ & $2500-3000$ & $3000-3500$ & $4000-5000$ and above \\
\hline Hebei Province & $1700-2400$ & $2100-3000$ & $2500-3500$ & $3500-4500$ and above \\
\hline
\end{tabular}


The nursing staff in pension institutions is generally older, the population between 40 and 50 years old accounts for more than $90 \%$, that of 30 to 40 years old is less than $10 \%$. And $92 \%$ of the nursing staff education is high school or lower. Most of nursing staff in Beijing and Tianjin are working after pre job training, and have certificates. General nursing staff needs care for 8 to 15 elderly, their work is heavy, but the level of wages doesn't match their workload. The average wages in Beijing is between 5000 yuan and 6000 yuan, between 4000 yuan and 5000 yuan in Tianjin, between 3000 yuan and 4000 yuan in Hebei province. Because of this, few people are willing to engage in nursing. The wage distribution of nursing staff in Beijing and Tianjin is also shown in Figure.3 and Figure.4.

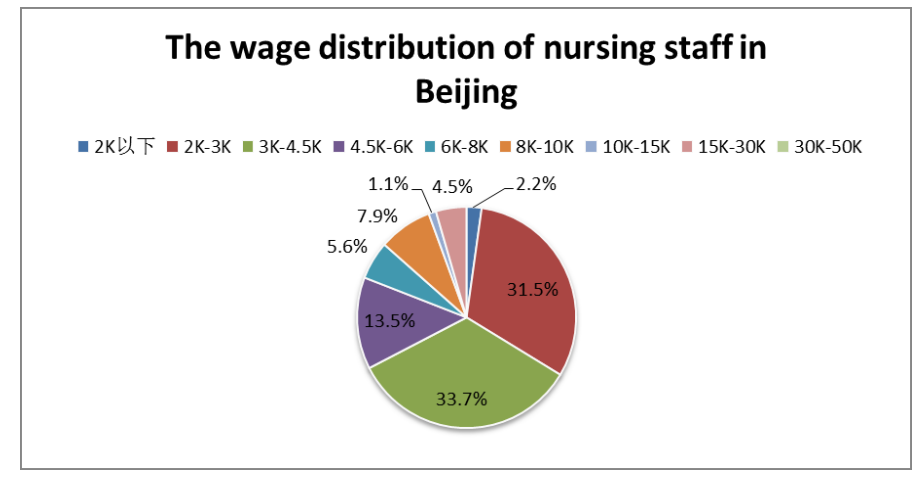

Figure.3 The wage distribution of nursing staff in Beijing

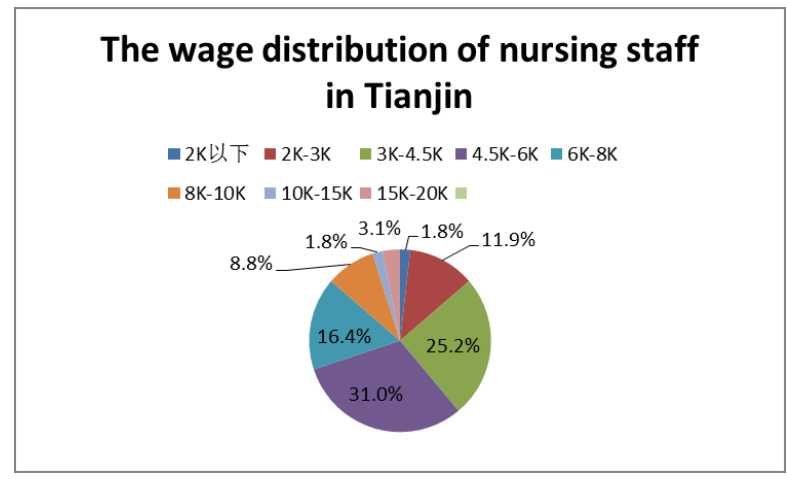

Figure. 4 The wage distribution of nursing staff in Tianjin

In addition, it is understood that more than half of elderly in Beijing-Tianjin-Hebei region is satisfied with the nursing service, nursing home, the surrounding environment of the pension institutions and the quality of the diet. And they think the medical services, internal facilities, entertainment activities need to be improved.

First, public pension institutions in China are not for profit, whose public property is obvious. The service was limited to the "three without" in city, "Five Guarantees" in rural area and the economic difficulties of widows and orphans, disabled, elderly, their duties within the scope of the service is non-competitive and non-exclusive, only to meet the basic conditions can enjoy the relevant pension services without preconditions, it belongs to the public service. With the advance of the "self-adoption" reform, public pension institutions began to charge, ordinary people (except that the "three without" elderly in city, "Five Guarantees" elderly in rural area) can enjoy the pension service after payment, make public pension institutions have competitive and exclusive, with private product characteristics. Due to historical reasons and path dependence dilemma of related system, the current public pension institutions are still supply public products and private products, two kinds of services at the same time, and there is no effective system to distinguish between the two types of service boundary, which leads to many problems in the current reform of public pension institutions. While the private pension institutions encouraged by the government, the number of institutions increased significantly and the elderly has diversified structure, because it is still in the initial stage, operation is difficult, many private pension institutions are still at a loss or with little profit. 
With the beginning of the a comprehensive public pension institutions reform in Beijing last year, brand and service output has become a new way to explore the transformation of public pension institutions. According to "Beijing public pension institutions operating system reform census report" (hereinafter referred to as the report) issued by the Beijing Municipal Civil Affairs Bureau displayed that, currently, the public pension institutions in Beijing reached 28 thousand beds, all of public pension institutions in whole city solved 11 thousand elderly of centralized pension. It is reported that among the public institutions in Beijing, 73 agencies have adopted a public build but private operation mode, which accounts for $37.4 \%$, it's mainly concentrated in the city of six districts and urban development zones. The Beijing commercial news reporter in an interview found that part of the civil affairs departments in Tianjin and Hebei Province are also beginning to look for the direction of the transformation of public institutions, which maybe reference to the model of Beijing.

In addition, from the limit to encourage and then guide, the threshold of the pension market for foreign investment in Beijing and even the whole Beijing-Tianjin-Hebei region is getting lower and lower. This also allows foreign investment to become a pool of fresh blood to stir regional endowment industry development. At the end of May last year, the "Reply of the State Council on the overall scheme of the comprehensive pilot scheme for the opening up of the service sector in Beijing" disclosure by GOV.cn, it officially opened the restrictions of foreign investment in Beijing, which will guide foreign investment in the field of nursing care for the elderly.

\section{Community Home-Based Care Status}

Community home-based care refers to the way of the elderly taking pension retirement life living in the family in accordance with our nation habits. It is based on the community as a platform to integrate a variety of service resources within the community, and provide meals, cleaning, bathing, medical aid and other services.

As an important part of the social security system, home-based care for the aged plays an important role in improving people's livelihood and promoting social harmony [11]. After years of exploration and practice, Beijing Municipality implemented home care (disabled) services in the socialization of home-based care services and established the socialized management and service, community health services, legal aid services, cultural services and other activities. By the end of 2012 in Tianjin Municipality, $80 \%$ of the elderly rely on the community to achieve home care, $10 \%$ of the elderly achieved government procurement services, $30 \%$ of the community had a day care service station for the elderly and the disabled, $60 \%$ of the community had achieved various types of elderly service organization networking. Elderly service team reached 50 thousand people, which has begun to take shape. And Hebei Province has opened community home cared experimental units in LangFang, Shijiazhuang, Cangzhou and other cities.

Zhang Xiaoyi, Liu Bangcheng (2011) think that the services provided by the home-based care for the aged is mainly for the elderly to provide life care, health care, psychological comfort and other social services.

Table 2 Comparison of home care needs in Beijing-Tianjin-Hebei region

\begin{tabular}{|l|l|}
\hline City & Pension service needs \\
\hline $\begin{array}{l}\text { Beijing } \\
\text { Municipality }\end{array}$ & $\begin{array}{l}\text { Day care, Psychological comfort, Medical care, } \\
\text { Legal aid }\end{array}$ \\
\hline $\begin{array}{l}\text { Tianjin } \\
\text { Municipality }\end{array}$ & Day care, Health care, Culture and entertainment \\
\hline Hebei Province & take day care and daily life as the principal thing \\
\hline
\end{tabular}


Table 2 gives a comparison of the demand for home care services in Beijing-Tianjin-Hebei region. From table 2, the basic need of the serviced is daily life care. This demand has been satisfied in Beijing-Tianjin-Hebei region. With the satisfaction of the basic needs, the served objects may produce more demand, such as psychological, spiritual needs and higher levels of demands. Relatively, the demand for home care services is diverse for elderly in Beijing and Tianjin. And it develops to the psychological comfort, legal aid and other all-round development. For elderly people in Hebei Province, their service demand of the home care is not high, and most demand is the basic necessities.

\section{Existing Problems}

\section{Lack of Pension Services Industry Standards}

In China, there are few documents on the standards of pension service. And most of them are based on descriptive language and lack of substantive guidance. At the same time, the documents related to the pension service industry are more scattered, lack of unity and systematic. Therefore, at present, the development of pension services industry in Beijing-Tianjin-Hebei region is a lack of standardization in terms of development and management. The provision of services is limited, and most of the content is limited to a small part.

\section{Development of Pension Services Is Unitary, Service, Technology and Functions Are Weak}

The pension services of Beijing-Tianjin-Hebei region are concentrated in the pension institutions, welfare or community, even in home, and carrying out some simple medical care or housekeeping services for the elderly. The elderly supplies, apartments for the elderly, the old culture and other services of pension services and supporting services are still at early stage.

\section{Data Sharing and Analysis Needs To Be Strengthened}

Data is important asset, which is an important part of the core values of the elderly. But pension services of Beijing-Tianjin-Hebei region are basically independent operation, pension data are generally concentrated in the Civil Affairs Bureau and the Health Bureau, each pension service platform doesn't achieve resource sharing. A lot of important information is generally hidden behind the data. Therefore, the pension data mining, integration and analysis need to be increased.

\section{Lack of Pension Services for the Versatile Talent}

Excellent pension service staff with medical care, psychological counseling and other professional knowledge is relatively rare. On this basis, the talent who understands network information management, intelligent terminal applications, data processing is fewer. At present, most of the people who are engaged in the service for the aged do not pass the professional training. It is always regarded that the people who do housekeeping work in the community will be equal to the pension service staff, which reduces the sense of self-worth of the personnel engaging in pension service, thus restricting the development of the pension industry.

\section{Lack of Medical Resources, the Cost is Too Heavy to Bear}

According to the survey, there are nearly $1 / 3$ of the patients hospitalized in the medical and health institutions are the elderly. Among them, the proportion of elderly patients in township hospitals and community health service centers was higher, accounting for $1 / 2$ or more.

In the area of Beijing-Tianjin-Hebei, the number of specialized hospitals for the elderly is very small. In rural areas, there is lack of professional medical services for the elderly. The elderly medical resources are seriously inadequate.

In addition, the average cost of hospitalization for elderly patients is far more than the average cost of hospitalization for non-elderly patients. Currently, the medical insurance policy and the new rural cooperative medical policy are mainly based on disease to make refund policy, in addition to the "Five 
Guarantees". There is no refund proportion policy for the elderly special groups. Besides, the cost of hiring nursing is heavy, often beyond the aged capacity.

\section{Countermeasures and Suggestions}

\section{To Achieve the Unity of the Three Places Pension Service Standards and Promote the Integration of Pension}

The government should improve relevant laws and regulations and policy provisions. It is necessary to ensure that the elderly population in different regions in the unified pension institutions enjoy equal pension security, get rid of the medical, pension and other aspects of administrative barriers. But also for the docking of pension service providers provide a fair competitive conditions and operating environment (Dong Lirui, 2016). Moreover, overall planning for administrative directives, market will and the law will be a prerequisite for coordinating the integration of Beijing-Tianjin-Hebei region elements of resource and cross reginal governance. The coordination of administrative will and market will provide a scientific planning, the law will provide the basic guarantee. In this regard, the proposition of the coordinated development of Beijing-Tianjin-Hebei, not only on the regional economic and social development proposition, but also on the improvement of governance mechanisms proposition. Improvement of governance mechanisms plays a far more important role than project implementation (Ji Fengyuan, 2016). Of course we should also avoid combat the enthusiasm of small private capital into aged service because of the high standard demand.

To Increase the Policy Support of the Three Governments to The Pension Service Industry, Promote The Coordinated Development Of Beijing-Tianjin-Hebei Pension Services Industry

Beijing-Tianjin-Hebei should make reasonable financial subsidy policy. The cooperative construction of pension service institutions should implement a unified financial subsidy standard. Because of the economic volume for Beijing-Tianjin-Hebei region, financial income level are also significantly different, government should give full consideration to the specific situation of the three region division of the proportion of investment. For Beijing and Tianjin that have the relatively abundant financial resources, the government can finance investment. Hebei Province can be invested in the area around Beijing and Tianjin because it has more abundant land resources. And the pension institutions, day care centers and nursing staff should be supported and subsided in the park (Liu Li, 2014).

In addition, the civil affairs departments should strictly review the regulatory system of pension services, while establishing the assessment mechanism of pension institutions. This can not only improve the service standards of the pension services industry, but also form the standardization of the elderly industry. They should evaluate the pension service institutions on professionalism and price.

\section{Improve the Basic Security Mechanism for the Coordinated Development of Pension Services}

In order to achieve the coordinated development of the pension services for Beijing-Tianjin-Hebei region, the government should improve the development of basic security mechanism as soon as possible (Sun Jianfu and Dai Luwei, 2015). First, they should improve the regional traffic. The regional traffic of Beijing-Tianjin-Hebei region has a certain foundation, but it is not perfect enough, especially the traffic between the cities and surrounding small cities is not smooth. We recommend that the highway, intercity rapid rail transit and other trunk roads should be built as soon as possible to achieve a radius of $100 \mathrm{~km}$ of Beijing and Tianjin about the scope of the highway traffic circle of 1 hour. Second, it's the cooperation of medical institutions. The Beijing elderly who is living out his life in retirement in Hebei must be able to see a doctor easily in the local. On one hand, there is a need to have a better local hospital; on the other hand, the health insurance is to be linked among the three places. Therefore, we suggest the well-known hospital in Beijing-Tianjin-Hebei region can cooperate 
with each other, support each other from two aspects of hardware and software, and improve their level of medical treatment. At the same time, the pension insurance cards should be interconnected by internet between Beijing-Tianjin-Hebei regions, so that no matter where the elderly live, the pension insurance card can be used to see a doctor (Li Xueyan and Meng Bin, 2010).

\section{Improve the Professional Quality of Nursing Staff and Volunteers}

The development of pension service industry needs a large number of high qualities and strong sense of responsibility of professional service personnel. In the training of pension service personnel, Hebei and Tianjin can learn from the Beijing's experience on training service personnel, make the idle labor force and the surplus labor begin working after the training, not only to provide professional services for the elderly, but also provide a large number of re-employment positions, which will solve the employment pressure of these groups. This requires the government to take the lead, the Ministry of civil affairs, the Ministry of human resources and the Ministry of education, Ministry of Finance and other related departments should support it. Employment training, service personnel treatment and professional occupation training and other aspects are needed to enhance the professional level of pension service personnel. They should put the training of service personnel into the long-term talent development plan, support additional professional and courses about pension services, take training program in order form and accelerate the development of pension service professionals.

\section{Acknowledgement}

This research was financially supported by National Social Science Fund (Project No. 15AGL001).

\section{References}

[1] Wen Kui. Blue Book of Beijing-Tianjin-Hebei: The Development Report of Beijing-Tianjin-Hebei (2013) - Carrying Capacity Measure and Countermeasure. Beijing: Social Science Literature Press, 2013

[2] Chen Yi. "Problems on the Pension Services Industry," Modern Economy Discussion, No.11, 2010

[3] Sun Jianfu, Dai Luwei. "The Environment, Objectives and Principles of Collaborative Development of Pension Service Industry in Beijing-Tianjin-Hebei," Economic Research Reference, No.63, pp. 41-46, 2015

[4] Li Jing, Han Xiaohu. "Under the Background of the Coordinated Development in Beijing-Tianjin-Hebei the Survey of the Offset Pension Willingness for Elderly in Beijing," Industry and Technology Forum, No.7, pp. 133-134, 2016.

[5] Luo Haiping and Ling Dan. "Countermeasures and Suggestions for Speeding Up the Development of Pension Service Industry in China,” Special Economic Zone, no. 9, 2013.

[6] Wang Jia. "Reasearch on the Development of Pension Service Industry Under the Background of Population Aging: A Case Study of Henan Province," Technology entrepreneurship monthly, No.5, 2011.

[7] Liu Yue. "China Pension Service Industry Development Status Quo, Problems and Countermeasures," Wenhui science and technology, No.7, 2015.

[8] Xiang Tian. "The Impact of Population Aging on the Development of Pension Industry in China," Labor and Social Security (Theory), No.6, 2012.

[9] Zhang Panpan. "Research on the Countermeasures of the Development of Social Pension Service Industry in China,” Merchant, No.17, 2016. 
[10] Wang Xiaochun, Fu Zhining and Wang Ning. "Research on the Construction of Social Pension Service System in Beijing-Tianjin-Hebei," Rural Economy and Science and Technology, No.10, pp.201-203, 2015.

[11] Ren Lanlan, Han Jingyao and Guo Danyun. "Comparison and Reference of Urban and Rural Pension Services in Beijing-Tianjin-Hebei," Cooperative Economy and Technology, No.15, pp.144-145, 2014.

[12] Zhang Xiaoyi and Liu Bangcheng." Study on the Model of Community Home Care Service Quality: A Case Study of Shanghai," Chinese Population Science, No.3, 2011.

[13] Dong Lirui." Research on the Coordinated Development of Pension Service Industry in Beijing-Tianjin-Hebei,” Managers, No.24, pp. 128, 2016.

[14] Ji Fengyuan. "Collaborative Development Plan of Beijing, Tianjin and Hebei," Docking Beijing and Tianjin- Beijing-Tianjin-Hebei Collaborative Development Forum (10), Lang Fang, 2016.

[15] Liu Li. "Collaborative Design of Pension Service System in Beijing-Tianjin-Hebei," Cooperative Economy and Technology, No.22, pp. 174-175, 2014.

[16] Liu Li. " Research on the Development of Pension Service Industry in the Capital Economic Circle," Cooperative Economy and Technology, No.8, pp. 179-181, 2016.

[17] Li Xueyan and Meng Bin. "New Ideas on the Development of Pension Housing Industry in Beijing, Tianjin and Hebei,” Urban Development Research, No.12, pp. 60-65, 2010. 